\title{
Pogitare
}

ARTIGO ORIGINAL

\section{PASSAGEM DE PLANTÃO DA ENFERMAGEM: DESENVOLVIMENTO E VALIDAÇÃO DE INSTRUMENTOS PARA QUALIFICAR A CONTINUIDADE DO CUIDADO}

\author{
Isabel Cristina Echer ${ }^{1}$ (1) \\ Fernanda Guarilha Boni ${ }^{1}$ (1) \\ Beatriz Cavalcanti Juchem ${ }^{2}$ (1) \\ Vanessa Monteiro Mantovani ${ }^{1}$ (1) \\ Simone Silveira Pasin ${ }^{2}$ (1) \\ Larissa Gussatschenko Caballero² \\ Amália de Fátima Lucena ${ }^{1}$ (1)
}

\section{RESUMO}

Objetivo: desenvolver e validar o conteúdo de instrumentos para padronizar a passagem de plantão da enfermagem.

Método: estudo de desenvolvimento e validação por consenso de especialistas, conduzido de janeiro a julho de 2019 em hospital do sul do Brasil. Participaram do estudo 24 profissionais de diferentes áreas, incluindo enfermeiros, técnicos e professores de enfermagem, com experiência na passagem de plantão hospitalar. Avaliou-se abrangência, clareza e pertinência dos itens dos instrumentos, sendo validados pelos especialistas sobre cada item dos instrumentos desenvolvidos, obtendo-se índice de concordância de $93 \%$.

Resultados: foram elaborados o "Formulário de Passagem de Plantão", contemplando identificação dos pacientes, informações clínicas e intercorrências de cada turno, e o "Procedimento Operacional Padrão para Passagem de Plantão", descrevendo atividades a serem realizadas para garantir a transmissão de informações precisas.

Considerações finais: os instrumentos elaborados podem nortear a passagem de plantão da enfermagem na prática clínica, promovendo a continuidade e segurança do cuidado.

DESCRITORES: Lista de Checagem; Avaliação em Enfermagem; Segurança do Paciente; Troca de Informações; Continuidade da Assistência ao Paciente.

\section{CAMBIO DE TURNO DE ENFERMERÍA: DESARROLLO Y VALIDACIÓN DE INSTRUMENTOS PARA CALIFICAR LA CONTINUIDAD DE LA ATENCIÓN}

\section{RESUMEN:}

Objetivo: desarrollar y validar el contenido de instrumentos para estandarizar el cambio de turno de Enfermería. Método: estudio para el desarrollo y la validación por consenso de especialistas realizado entre enero y julio de 2019 en un hospital del sur de Brasil. En el estudio participaron 24 profesionales de diferentes áreas, incluidos enfermeros, técnicos y profesores de Enfermería, con experiencia en el cambio de turno en hospitales. Se evaluó el alcance, la claridad y la pertinencia de los ítems de los instrumentos y los especialistas lo validaron en cada ítem de los instrumentos desarrollados, obteniéndose un índice de concordancia del 93\%. Resultados: se elaboraron dos documentos, a saber: "Formulario de Cambio de Turno", que contempla la identificación de los pacientes, información clínica y complicaciones de cada turno, y el "Procedimiento Operativo Estándar para Cambio de Turno", que describe actividades que deben realizarse para garantizar la transmisión de información precisa. Consideraciones finales: los instrumentos elaborados pueden dirigir el cambio de turno de Enfermería en la práctica clínica, promoviendo así la continuidad y seguridad de la atención.

DESCRIPTORES: Lista de verificación; Evaluación en Enfermería; Seguridad del paciente; Intercambio de información; Continuidad de la asistencia al paciente. 
O cuidado seguro ao paciente é fonte de atenção contínua nas diversas organizações de saúde a nível mundial. Especialmente no âmbito hospitalar, o paciente é assistido por diversos profissionais de saúde, o que torna a comunicação sobre suas informações clínicas essencial para a continuidade do cuidado e para garantir a segurança assistencial(1).

Neste contexto, a passagem de plantão da equipe de enfermagem é uma atividade fundamental, sendo um mecanismo estratégico para a organização do trabalho (2). Por meio desta atividade, é possível assegurar a continuidade da assistência aos pacientes nos diferentes turnos de trabalho, independente das mudanças de equipes.

Durante a realização da passagem de plantão, devem ser abordadas questões referentes à avaliação do estado de saúde do paciente, intercorrências e assuntos de interesse institucional. Ressalta-se que o conteúdo das informações transmitidas deve ser claro e objetivo, pois a ocorrência de falhas de comunicação pode ocasionar prejuízos na assistência e danos à saúde dos pacientes ${ }^{(3)}$.

Com a implementação de uma comunicação efetiva e a organização das informações transmitidas entre as equipes de enfermagem, eventos relacionados ao processo de assistência aos pacientes e situações de risco podem ser minimizados ${ }^{(4)}$. Todavia, muitas vezes, as equipes de enfermagem não possuem um instrumento capaz de direcionar a comunicação de forma organizada e factível, sem extrapolar o horário de seu turno de trabalho, o que gera preocupação às lideranças das instituições. Nessa perspectiva, o uso de instrumentos padronizados para a passagem de plantão tem se mostrado uma ferramenta útil para tornar a comunicação efetiva, e reduzir possíveis falhas e danos ${ }^{(5)}$.

A literatura apresenta estudos sobre 0 uso de instrumentos padronizados que norteiam as ações da enfermagem nos seus diversos campos de atuação, o que tem repercutido positivamente para uma prática assistencial pautada na qualidade e segurança do paciente ${ }^{(4-7)}$. No entanto, persiste uma lacuna no que diz respeito a instrumentos para nortear a passagem de plantão da enfermagem que tenham sido vinculados a um procedimento operacional padrão (POP), que gera maior detalhamento à sua aplicabilidade e, consequentemente, agrega segurança ao cuidado dos pacientes.

Diante deste cenário, com a intenção de qualificar a comunicação entre a equipe de enfermagem durante a passagem de plantão e prevenir a ocorrência de eventos adversos, motivou-se o desenvolvimento e validação de um formulário com informações padronizadas para a transferência do cuidado do paciente, acompanhado de um POP para normatizar essa atividade. Portanto, a questão norteadora deste estudo foi: como promover um processo padronizado de passagem de plantão entre os profissionais de enfermagem dos diferentes turnos, otimizando o tempo e a continuidade do cuidado seguro ao paciente?

Para responder a esta questão, foi delineado este estudo com o objetivo de desenvolver e validar o conteúdo de instrumentos para padronizar a passagem de plantão da enfermagem. A relevância deste estudo está em fornecer elementos para padronizar a transferência do cuidado entre os turnos da equipe de enfermagem e otimizar o tempo dispendido para esta atividade. Acredita-se que a partir da padronização e implementação dos instrumentos relacionados, será possível qualificar a comunicação entre os profissionais de enfermagem durante as jornadas de trabalho.

\section{MÉTODO}


Trata-se de um estudo de desenvolvimento e validação de conteúdo de instrumentos por consenso de especialistas. A validação por consenso possibilita o alcance de opinião coletiva ou acordo entre especialistas sobre uma temática específica, e é bastante utilizada na área da enfermagem, por possibilitar a padronização das práticas realizadas pelos profissionais ${ }^{(8-9)}$.

O estudo foi realizado no período de janeiro a julho de 2019, com a participação de 24 profissionais de enfermagem, divididos em 16 enfermeiros, cinco professores e três técnicos de enfermagem de diferentes unidades de internação clínica, cirúrgica e pediátrica de um hospital universitário de grande porte no sul do Brasil. Todos os participantes deste comitê de especialistas tinham experiência na prática clínica e na passagem de plantão hospitalar por pelo menos cinco anos, sendo estes os critérios de inclusão no estudo.

Foram realizadas reuniões semanais durante os meses de fevereiro a abril de 2019, totalizando 11 encontros de 60 minutos, tendo como pauta os seguintes temas: objetivo do grupo de trabalho, problemática atual e método de trabalho proposto. No primeiro encontro, foram descritos e mapeados os cenários e as particularidades de cada unidade de internação e suas dificuldades relacionadas à passagem de plantão.

Nas reuniões do mês de março de 2019, foram debatidas sugestões de melhoria do processo de passagem de plantão e da tomada de decisão. Visando sistematizar esta ação, foram determinadas atividades e responsabilidades da equipe de enfermagem a serem realizadas antes da passagem de plantão pela equipe que irá passar o turno, atividades a serem realizadas durante a passagem de plantão, na qual há troca de informações entre as duas equipes, e atividades a serem realizadas após a passagem de plantão péla equipe que está assumindo o turno.

Além disso, durante as discussões, foram desenvolvidos os itens que iriam compor o formulário padrão de passagem de plantão, norteado pelo referencial teórico utilizado no hospital para a execução do processo de enfermagem ${ }^{(10-11)}$, além de uma revisão da literatura nas bases de dados Pubmed, Medline e LILACS, com os descritores: lista de checagem, avaliação em enfermagem, cuidados de enfermagem, segurança do paciente, equipe de enfermagem: organização e administração, e informação e comunicação em saúde ${ }^{(2,4-6)}$.

Uma vez definidos pelos especialistas os itens do instrumento de passagem de plantão, foi realizado um teste piloto para verificar a sua aplicabilidade na prática profissional. Nesta ocasião, foram acolhidas as sugestões da equipe para refinamento do material.

A escolha da unidade para o teste piloto foi feita utilizando-se uma matriz de relação entre critérios específicos como: semelhança do processo quando comparado a outras unidades, o que possibilitaria maior facilidade de disseminação de melhorias; complexidade do processo de passagem de plantão, caracterizado por múltiplos cenários de cuidado e elevado número de pacientes e membros da equipe; disponibilidade das equipes para o desenvolvimento de ciclos de melhoria durante a fase de testes.

O teste piloto foi realizado em uma unidade de internação clínica de 45 leitos, com equipe composta por 15 enfermeiros e 47 técnicos de enfermagem distribuídos nos diferentes turnos. $O$ instrumento desenvolvido foi apresentado à equipe assistencial da unidade, que o aplicou na passagem de plantão com base em um roteiro de apoio. Os especialistas observaram a aplicação do instrumento durante cinco dias, anotando pontos fortes e fragilidades do processo de passagem de plantão. Posteriormente, melhorias foram incorporadas no instrumento, dentre as quais se destaca a redução das informações, organização dos itens de verificação de modo a seguir a ordem do exame físico, ênfase nas escalas de risco, adequação do layout para deixar mais objetivo e adaptado aos turnos de trabalho. Também foi identificada a necessidade de reorganizar e divulgar entre as equipes assistenciais o papel do guardião da passagem de plantão, visando evitar interrupções.

Paralelamente, foi desenvolvido pelos especialistas o POP relacionado à passagem 
de plantão, que descreve as atividades a serem realizadas antes, durante e imediatamente após este processo, o qual também foi testado e refinado.

Uma vez concluída a etapa de desenvolvimento do Formulário de Passagem de Plantão e do POP, foi realizada a validação por consenso dos especialistas, que avaliaram a abrangência, clareza e pertinência dos itens dos instrumentos. Por fim, solicitou-se a apreciação dos membros da comissão institucional de normas e rotinas, de modo a refinar o que havia sido validado.

A versão final dos formulários foi determinada com a concordância de especialistas e consulta à literatura científica nacional e internacional sobre esta temática, bem como estratégias de comunicação e educação para implementação de melhorias (1-2,4-6,12-14). $^{(20)}$ 3.257.557.

Este projeto foi aprovado pelo Comitê de Ética em Pesquisa da instituição com $n^{\circ}$

\section{RESULTADOS}

Com a expertise de 16 enfermeiros, cinco professores e três técnicos de enfermagem de diferentes unidades de internação da instituição com amplo conhecimento sobre a temática, foram elaborados e validados dois instrumentos a fim de padronizar e sistematizar a passagem de plantão. Para tanto, foram necessárias quatro reuniões deste comitê de especialistas, de modo a chegar a um índice de concordância de $93 \%$ sobre cada um dos itens dos instrumentos desenvolvidos.

A versão final dos formulários incluiu itens visando maior segurança na transição do cuidado, tais como identificação do paciente, motivo da internação e história prévia, avaliação de escalas de risco, evolução clínica, aceitação alimentar, uso de drenos e/ou dispositivos, eliminações vesicais/intestinais, intercorrências, exames e/ou procedimentos pendentes.

O primeiro resultado deste estudo teve como produto um instrumento denominado "Formulário de Passagem de Plantão", que contempla dados de identificação de cada paciente e as informações clínicas mais relevantes, além de itens padrão a serem informados, com espaço para que enfermeiros e técnicos de enfermagem possam descrever as ocorrências em cada turno. O formato e o conteúdo do instrumento podem ser visualizados na Figura 1. 
Data de validade de $/$ à $/$ I

\begin{tabular}{|c|c|c|c|}
\hline IDENTIFICAÇÃO & MANHÃ & TARDE & NOITE \\
\hline $\begin{array}{l}\text { Leito: } \\
\text { Nome: } \\
\text { Prontuário: } \\
\text { Idade: } \\
\text { Motivo atual de internaçào: } \\
\text { História Prévia: } \\
\text { Alergias: } \\
\text { Braden: SAK: } \\
\text { Data internaçāo: }\end{array}$ & 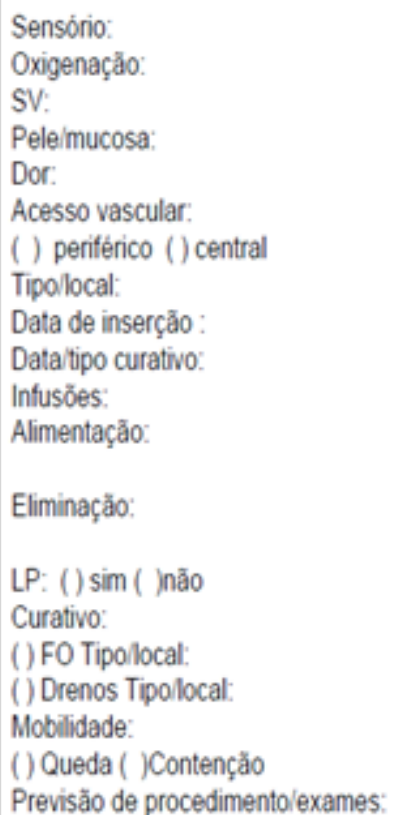 & & \\
\hline
\end{tabular}

Figura 1 - Formulário de passagem de plantão com informações a serem transmitidas entre os turnos de trabalho. Porto Alegre, RS, Brasil, 2019

Fonte: Autores (2019).

Legenda: SV=sinais vitais; LP=lesão por pressão; FO=ferida operatória; SAK (Severo-Almeida-Kuchenbecker) avalia predição de risco de quedas

O POP para passagem de plantão foi o segundo produto desenvolvido e validado, e elenca as atividades que necessitam ser realizadas antes, durante e após a passagem de plantão, visando garantir que a operacionalização da transmissão das informações seja efetiva. $O$ seu conteúdo está descrito na Figura 2. 


\section{Atividades a serem realizadas antes da passagem de plantão}

- Manter atualizados os registros no prontuário eletrônico, contracheque e formulário da passagem de plantão

- Verificar pendências relacionadas aos pacientes e ao ambiente

- Realizar troca de informaçōes finais entre enfermeiros e técnicos de enfermagem

- Revisar escala de distribuição dos pacientes e tarefas da equipe que irá receber o plantão

- Revisar infusões instaladas para evitar, quando possível, que o término ocorra durante a passagem de plantão

- Verificar alterações da prescrição médica, tais como inclusão/exclusão de medicamentos, previsão de procedimentos a serem realizados e resultados de exames

- Preencher o formulário de passagem de plantão incluindo as principais alterações ocorridas em seu turno de trabalho

- Definir técnico de enfermagem que ficará responsável para atendimento das demandas da unidade durante esse período, com vistas a reduzir interrupçōes e garantir o atendimento das necessidades dos pacientes

\section{Atividades a serem realizadas durante a passagem de plantão}

- Respeitar e estar presente no horário de início ao término da passagem de plantão

- Sentar lado a lado, enfermeiros e técnicos de enfermagem, transmissores e receptores das informações, utilizando o formulário de passagem de plantão e as prescrições do paciente

- Transmitir informações gerais e importantes sobre particularidades da unidade, quando necessário

- Relatar somente alterações que ocorreram durante o turno de trabalho sobre o paciente e outras informações importantes como pendências (ex: preparos de exames e coletas) de forma clara e objetiva

- Entregar para o colega receptor os documentos (formulário da passagem de plantão, contracheques e etiquetas de medicamentos)

- Complementar as informaçōes relatadas pelo enfermeiro e técnico de enfermagem sempre que necessário, evitando redundâncias

- Transmitir o que for essencial para dar continuidade à assistência dos pacientes

- Cabe ao guardião da passagem de plantão atender às campainhas, trocar terapias infusionais intermitentes, salinizar acessos venosos, realizar cuidados com necessidades físiológicas (comadres/papagaios), bem como auxiliar deslocamentos até o sanitário, receber e anotar recados para a equipe de enfermagem que está recebendo o plantão.

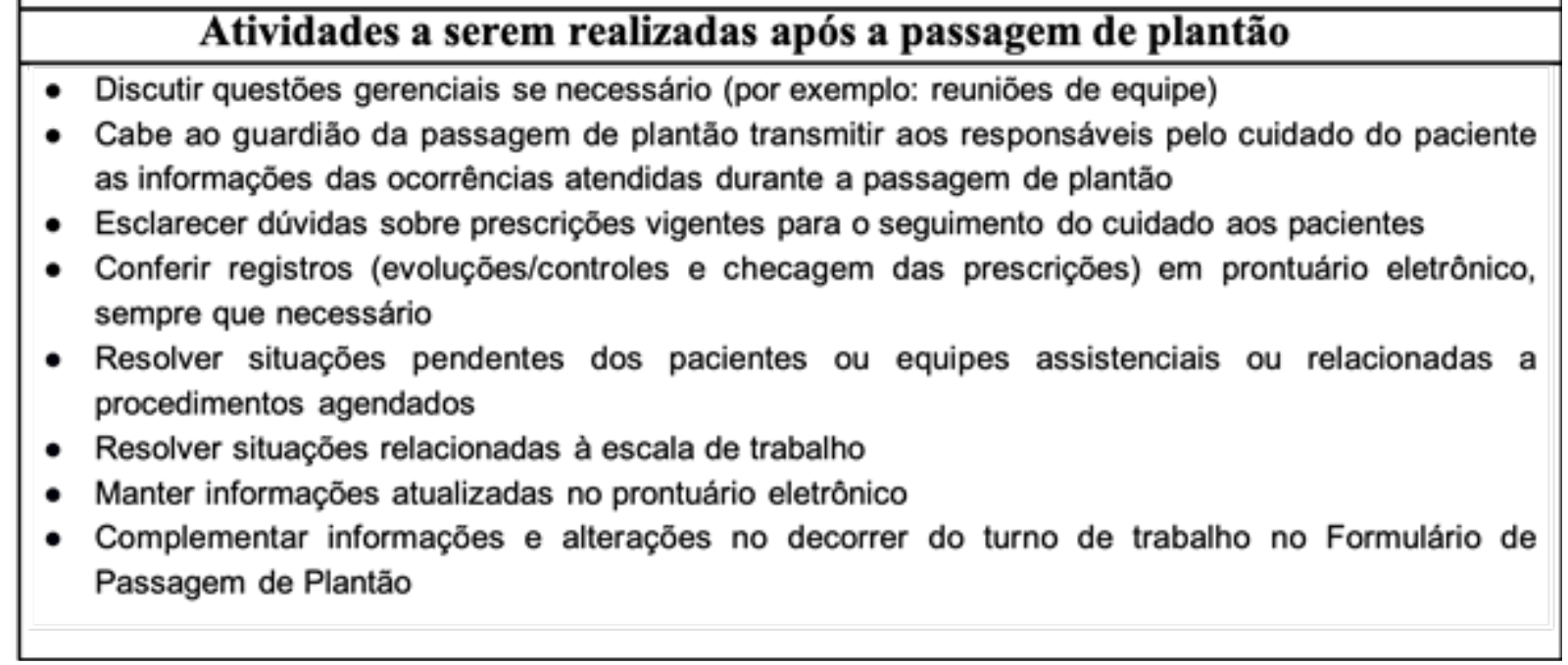

Figura 2 - "POP para passagem de plantão" com as atividades a serem desenvolvidas pela equipe de enfermagem antes, durante e após a passagem de plantão. Porto Alegre, RS, Brasil, 2019

Fonte: Autores (2019). 
Este estudo, realizado com diferentes profissionais de enfermagem, permitiu elaborar e validar um Formulário e um POP para passagem de plantão, de modo a tornar esta atividade organizada e efetiva. A transferência do cuidado representa um momento de transmissão de informações importantes entre as equipes de saúde. Dados omitidos ou mal interpretados podem comprometer a segurança do paciente, levando a erros ou outros resultados negativos para o paciente e sistema de saúde ${ }^{(12)}$. Desta forma, os formulários validados neste estudo podem qualificar a passagem de plantão da equipe de enfermagem e assegurar um cuidado seguro ao paciente.

Dados da Joint Commission of Accreditation of Healthcare Organizations apontam que mais da metade dos eventos adversos são causados por falhas na comunicação entre os profissionais ${ }^{(15)}$. Visando reduzir a incidência desses eventos por meio de melhorias específicas nos processos assistenciais, foram propostas as seis Metas Internacionais de Segurança do Paciente, sendo a primeira a que trata da identificação correta do paciente e a segunda da comunicação efetiva entre membros da equipe de saúde ${ }^{(16)}$.

Nessa perspectiva, para garantir que os cuidados e o plano terapêutico sejam executados de forma segura, a primeira parte do formulário apresenta dados essenciais de identificação: número do leito, nome completo e prontuário. Outras informações relevantes também são contempladas, como idade, data e causa principal da internação, história prévia, alergias, escalas para risco de quedas e de lesão por pressão.

Tão importante quanto a identificação correta são os registros acerca do cuidado prestado e da evolução clínica dos pacientes. A segurança do cuidado em saúde, assim como a continuidade das práticas terapêuticas, é dependente da qualificação dos profissionais, somado aos aspectos administrativos passíveis de padronização como os registros e organização das atividades assistenciais ${ }^{(7)}$.

Nesse sentido, o documento construído também contempla espaço destinado ao preenchimento de informações referentes ao sensório, oxigenação, sinais vitais, integridade da pele e mucosas, histórico de dor, uso de dispositivos vasculares incluindo tipo, local e datas de inserção e do curativo, infusões venosas, tipo de dieta, eliminações, presença e descrição de lesão por pressão, ferida operatória/drenos, mobilidade e previsão de procedimento/exames a serem realizados. Além disso, há espaços específicos para os turnos "Manhã", "Tarde" e "Noite", para que no decorrer da jornada de trabalho os profissionais descrevam dados sobre a evolução do estado de saúde do paciente.

Conforme a Classificação das Intervenções de Enfermagem, na intervenção denominada Passagem de Plantão, estes dados são corroborados e apontados como importantes atividades a serem executadas pelo enfermeiro(17). Destaca-se ainda a importância de informar de forma sucinta o histórico do paciente, motivo de internação e tratamento, bem como os cuidados de enfermagem necessários.

É importante ressaltar que o Formulário de Passagem de Plantão seguiu as premissas de referencial teórico que aborda as necessidades do paciente na sua integralidade ${ }^{(11)}$. Entretanto, foi necessária uma síntese para que fosse aplicável, considerando o intervalo de tempo que a equipe dispõe para esta atividade. Assim, visando otimizar e organizar a passagem de plantão, foi validado o POP contemplando as atividades a serem realizadas antes, durante e após a troca de turno.

O desenvolvimento e uso de POP na prática assistencial por profissionais de saúde é de extrema relevância, pois possibilita a padronização do cuidado, impactando diretamente na segurança do paciente e da equipe ${ }^{(18-19)}$. Nesta perspectiva, um estudo evidenciou que enfermeiros reconhecem a importância dos POP e a necessidade de uma equipe qualificada para implementá-los na prática clínica, priorizando a qualidade do atendimento 
e minimizando barreiras existentes ${ }^{(20)}$.

Uma revisão de literatura sobre transferência do cuidado envolvendo pacientes em pós-operatório identificou associação entre problemas de comunicação e a ocorrência de eventos adversos, apontando recomendações para aprimorar o processo de comunicação entre as equipes. Dentre estas, salienta-se a importância da padronização do processo de transferência de informações, assegurando que estas estejam completas e acuradas, pelo uso de um instrumento para guiar a comunicação. Além disso, indo ao encontro da literatura, destaca-se a importância de um local apropriado para sua realização, que assegure a privacidade do paciente e o sigilo das informações transmitidas, comprometendo, assim, os profissionais envolvidos e valorizando a atividade como parte do processo de cuidar ${ }^{(13)}$.

Estudo identificou que a utilização de checklist contribui para a gestão do cuidado, qualifica a assistência e a segurança dos pacientes. Entretanto, existe a necessidade da criação de uma cultura voltada para a corresponsabilização e o envolvimento de todos os membros da equipe ${ }^{(21)}$. Estes achados vêm ao encontro da proposta deste estudo, na medida que pode contribuir na conscientização da equipe para a passagem de plantão, na proteção do ambiente para evitar interrupções, na padronização das informações a serem transmitidas, além de otimizar os custos com o tempo dispendido nesta atividade.

Além destes aspectos, uma passagem de plantão bem estruturada, com uso de ferramentas de padronização, desempenha importante papel na formação de estudantes, pois os auxilia a se tornarem organizados, compreendendo melhor o processo de cuidado dos pacientes e engajados na cultura de segurança ${ }^{(14)}$. Considerando que a instituição campo deste estudo é referência na formação de profissionais de saúde e possui importante rotatividade de colaboradores, a implantação do POP é uma importante estratégia no alinhamento das equipes para o uso do Formulário da Passagem de Plantão sem que haja discrepância na qualidade das informações transmitidas.

Estudo examinou o impacto de um Sistema Integrado para Transferência de Cuidado de Enfermagem na satisfação dos enfermeiros com a passagem de plantão e as mudanças na prática. Os resultados foram positivos, melhorando a satisfação e ampliando o acesso às informações sobre os pacientes e para os membros da equipe de saúde das diferentes unidades da instituição(22). Além disso, espera-se que os registros em saúde sejam completos, acurados, objetivos e concisos, com a possibilidade de serem submetidos a auditoria.

Outro ponto importante é a qualidade dos registros efetuados, reflexo da assistência prestada, tendo-se os documentos do paciente e as suas respectivas informações registradas como elemento chave para a condução do tratamento, cuja segurança na guarda e no acesso é imperativa ${ }^{(23)}$. Destacam-se três objetivos fundamentais que devem ser assegurados para certificar a qualidade do registro: garantia de confidencialidade, grau de integridade dos dados armazenados e amplitude de disponibilidade das informações ${ }^{(24)}$. Reitera-se, ainda, que os registros em saúde podem subsidiar ações de gestão, vigilância, ensino e pesquisa, com destaque para os cuidados éticos na geração e manipulação dos dados dos pacientes ${ }^{(25)}$.

Nesse sentido, a responsabilidade da enfermagem é notável pelo fato de acompanhar o paciente em todos os momentos de sua internação, gerenciando assim as informações e o cuidado entre os diferentes turnos e nos mais diversos cenários da instituição, não esquecendo as áreas de apoio (laboratório, serviços de imagem e diagnóstico, entre outros). Essa continuidade do processo de cuidar mostra-se frágil quando a equipe não segue sistematicamente suas ações, possibilitando que falhas de comunicação na transição do cuidado coloquem o paciente em risco e infrinjam questões ético legais.

Cabe ao enfermeiro o planejamento, organização, execução e avaliação dos serviços de enfermagem, e a negligência de alguma dessas etapas pode ocasionar interrupção do cuidado dispendido aos pacientes ${ }^{(26)}$. Assim, a uniformização das informações das práticas assistenciais asseguradas pela utilização de um Formulário de Passagem de Plantão e um POP visam garantir a transferência do cuidado de maneira eficaz e segura, além de 
evidenciar de forma concisa as habilidades dos enfermeiros em tomadas de decisões, atitudes de liderança, habilidades técnicas, comprometimento e autonomia frente ao processo de cuidar.

Dentre os fatores descritos, cabe salientar as implicações trabalhistas vigentes: a equipe de enfermagem não deve ultrapassar sua jornada de trabalho. Assim, a reorganização do processo de passagem de plantão com procedimentos bem descritos possibilita a otimização do tempo dispendido, além da qualidade da informação, obedecendo os preceitos legais da profissão.

Como limitação, destaca-se o fato deste estudo relatar apenas a construção dos instrumentos, assim, sugere-se a realização de estudos mais robustos para monitorar a qualidade da transmissão das informações após a padronização da passagem de plantão na instituição. No entanto, reitera-se que os instrumentos aqui apresentados podem contribuir para a efetividade da transferência do cuidado em diferentes cenários da prática assistencial de enfermagem.

\section{CONSIDERAÇÕES FINAIS}

Odesenvolvimento do Formulário e do POP para passagem de plantão da enfermagem forneceu elementos norteadores para garantir a qualidade deste processo, contemplando as principais informações para a transferência segura do cuidado aos pacientes, no tempo previsto. O fato de ter sido desenvolvido e validado de forma participativa entre os membros que estão diretamente na assistência de enfermagem colaborou para a aceitação das alterações propostas e a qualificação do processo na prática clínica.

Desta forma, como sugestão de aprimoramento, sugere-se o acompanhamento da adesão das equipes ao uso do Formulário de passagem de plantão, operacionalizado conforme o POP, assim como a avaliação da sua efetividade na prática clínica. Estes resultados contribuem para a sistematização do trabalho do enfermeiro com base em dados científicos, importantes para o desenvolvimento da profissão e o empoderamento de todas as suas categorias, de forma a torná-los os verdadeiros protagonistas da saúde, conforme desafio da campanha Nursing Now no ano de 2020.

\section{REFERÊNCIAS}

1. Dusek B, Pearce N, Harripaul A, Lloyd M. Care Transitions: A Systematic Review of Best Practices. J Nurs Care Qual. [Internet]. 2015 [acesso em 12 jan 2020]; 30(3). Disponível em: https://doi.org/10.1097/ NCQ.0000000000000097.

2. Silva MF da, Anders JC, Rocha PK, Souza AIJ de, Burciaga VB. Communication in nursing shift handover: pediatric patient safety. Texto contexto - enferm. [Internet]. 2016 [acesso em 12 jan 2020]; 25(3). Disponível em: https://doi.org/10.1590/010407072016003600015.

3. Agência Nacional de Vigilância Sanitária (ANVISA). Boletim Informativo: segurança do paciente e qualidade em serviços de saúde. [Internet]. 2011 [acesso em 19 jan 20]; 1(1). Disponível em: https:// www20.anvisa.gov.br/segurancadopaciente/index.php/publicacoes/item/01-seguranca-do-paciente-equalidade-em-servicos-de-saude.

4. Olino L, Gonçalves A de C, Strada JKR, Vieira LB, Machado MLP, Molina KL, et al. Effective communication for patient safety: transfer note and Modified Early Warning Score. Rev. gaúcha 
enferm. [Internet]. 2019 [acesso em 20 jan 2020]; 40(spe). Disponível em: https://doi.org/10.1590/19831447.2019.20180341.

5. Corpolato RC, Mantovani M de F, Willig MH, Andrade LAS de, Mattei ÂT, Arthur JP. Standardization of the duty shift in a General Adult Intensive Care Unit. Rev. bras. enferm. [Internet]. 2019 [acesso em 25 jan 2020]; 72(supl1). Disponível em: https://doi.org/10.1590/0034-7167-2017-0745.

6. Silva SG da, Nascimento ERP do, Hermida PMV, Sena AC de, Klein TCR, Pinho FM de. Checklist para passagem de plantão de pacientes em pós-operatório imediato na admissão em terapia intensiva.

Enferm. foco. [Internet]. 2016 [acesso em 27 abr 20]; 7(1). Disponível em: https://doi.org/10.21675/2357707X.2016.v7.n1.658.

7. Ferreira RC, Montanari FL, Ribeiro E, Correia MDL, Manzoli JPB, Duran ECM. Elaboração e validação de instrumento de assistência de enfermagem para pacientes em unidades de terapia intensiva. Cogitare enferm. [Internet]. 2018 [acesso em 13 mar 2020]; 23(4). Disponível em: http://dx.doi.org/10.5380/ ce.v23i4.57539.

8. Azzolin K, Souza EN de, Ruschel KB, Mussi CM, Lucena A de F, Rabelo ER. Consensus on nursing diagnoses, interventions and outcomes for home care of patients with heart failure. Rev. gaúca enferm. [Internet]. 2012 [acesso em 25 jan 2020]; 33(4). Disponível em: https://doi.org/10.1590/S198314472012000400007.

9. Pinheiro J de Q, Farias TM, Abe-Lima JY. Painel de especialistas e estratégia multimétodos: reflexões, exemplos, perspectivas. Psico. [Internet]. 2013 [acesso em 25 jan 2020]; 44(2). Disponível em: https:// revistaseletronicas.pucrs.br/ojs/index.php/revistapsico/article/view/11216.

10. Herdman TH, Kamitsuru S, organizadores. Diagnósticos de Enfermagem da NANDA-I: definições e classificação, 2018-2020. 11. ed. Porto Alegre: Artmed; 2017.

11. Horta WA. Processo de Enfermagem. 16. ed. São Paulo: EPU; 2005.

12. Foster-Hunt T, Parush A, Ellis J, Thomas M, Rashotte J. Information structure and organisation in change of shift reports: An observational study of nursing hand-offs in a Paediatric Intensive Care Unit. Intensive crit. care nurs. [Internet]. 2015 [acesso em 28 jan 2020]; 31(3). Disponível em: http://dx.doi. org/10.1016/j.iccn.2014.09.004.

13. Segall N, Bonifacio AS, Schroeder RA, Barbeito A, Rogers D, Thornlow DK, et al. Can we make postoperative patient handovers safer? A systematic review of the literature. Anesth Analg [Internet]. 2012 [acesso em 1 fev 2020]; 115(1). Disponível em: http://dx.doi.org/10.1213/ANE.0b013e318253af4b.

14. Lim F, Pajarillo EJY. Standardized handoff report form in clinical nursing education: an educational tool for patient safety and quality of care. Nurse educ today. [Internet]. 2016 [acesso em 05 fev 2020]; 37. Disponível em: http://dx.doi.org/10.1016/j.nedt.2015.10.026.

15. The Joint Commission (US). Improving America's hospital: the Joint Commission's annual report on quality and safety 2007. [Internet]. Oakbrook Terrace: JCl; 2007 [acesso em 18 maio 2020]. Disponível em: https://www.jointcommission.org/assets/1/6/2007 Annual Report.pdf.

16. Joint Commission International (US). Padrões de acreditação da joint commission international para hospitais. 6. ed. Oakbrook Terrace: JCl; 2017.

17. Bulechek GM, Butcher HK, Dochterman JM, Wagner CM, organizadores. Classificação das intervenções de enfermagem (NIC). 6. ed. Rio de Janeiro: Elsevier; 2015.

18. Pereira LR, Carvalho MF, Santos JS, Machado GAB, Maia MAC, Andrade RD. Avaliação de procedimentos operacionais padrão implantados em um serviço de saúde. Arq. Ciênc. Saúde. [Internet]. 2017 [acesso em 27 abr 2020]; 24(4). Disponível em: https://docs.bvsalud.org/biblioref/2019/12/1046771/ a9.pdf.

19. Nascimento CCL do, Oliveira J das GC, Silva BV da C, Santos AAM dos, Tota J do S de S, Silva GHV da. Construção de procedimento operacional padrão para sala de imunização. Rev. eletrônica acervo 
saúde [Internet]. 2019 [acesso em 27 abr de 2020]; 11(9). Disponível em: https://doi.org/10.25248/reas. e389.2019.

20. Walter R da R, Gehlen MH, llha S, Zamberlan C, Freitas HMB de, Pereira FW. Procedimento operacional padrão no ambiente hospitalar: percepção de enfermeiros. J. res. Fundam. Care. Online [Internet]. 2016 [acesso em 29 abr 2020]; 8(4). Disponível em: http://www.seer.unirio.br/index.php/ cuidadofundamental/article/view/4413.

21. Cardoso ASF, Muller S, Echer IC, Rabelo-Silva ER, Boni FG, Ribeiro AS. Elaboração e validação de checklist para administração de medicamentos para pacientes em protocolos de pesquisa. Rev. gaúcha enferm. [Internet]. 2019 [acesso em 11 jun 2020]; 40(spe). Disponível em: https://doi.org/10.1590/19831447.2019.20180311.

22. Johnson $M$, Sanchez $P$, Zheng $C$. The impact of an integrated nursing handover system on nurses' satisfaction and work practices. J Clin Nurs. [Internet]. 2015 [acesso em 05 fev 2020]; 25(1-2). Disponível em: http://dx.doi.org/10.1111/jocn.13080.

23. Vasconcellos MM, Gribel EB, Moraes IHS de. Registros em saúde: avaliação da qualidade do prontuário do paciente na atenção básica, Rio de Janeiro, Brasil. Cad. saúde pública. [Internet]. 2008 [acesso em 10 fev 2020]; 24(supl.1). Disponível em: https://doi.org/10.1590/S0102-311X2008001300021.

24. Haas S, Wohlgemuth S, Echizen I, Sonehara N, Müller G. Aspects of privacy for electronic health records. Int J Med Inform. [Internet]. 2011 [acesso em 11 fev 2020]; 80(2). Disponível em: http://dx.doi. org/10.1016/j.ijmedinf.2010.10.001.

25. Ministério da Saúde (BR). Departamento de Monitoramento e Avaliação do SUS. Política Nacional de Informação e Informática em Saúde [Internet]. Brasília: Ministério da Saúde; 2016 [acesso em 15 jan 2020]. Disponível em: http://bvsms.saude.gov.br/bvs/publicacoes/politica nacional infor informatica saude 2016.pdf.

26. Conselho Federal de Enfermagem. Decreto n. 94.406, 08 de junho de 1987. Regulamenta a Lei n. 7.498, 25 de junho de 1986 que dispõe sobre o exercício da Enfermagem e dá outras providências. [Internet]. Brasília: 1987. [acesso em 15 fev 20]; Disponível em: http://www.cofen.gov.br/ decreto-n-9440687 4173.html. 
COMO REFERENCIAR ESTE ARTIGO:

Echer IC, Boni FG, Juchem BC, Mantovani VM, Pasin SS, Caballero LG, et al. Passagem de plantão da enfermagem: desenvolvimento e validação de instrumentos para qualificar a continuidade do cuidado. Cogitare enferm. [Internet]. 2021 [acesso em "colocar data de acesso, dia, mês abreviado e ano"]; 26. Disponível em: http://dx.doi. org/10.5380/ce.v26i0.74062.

Recebido em: 26/05/2020

Aprovado em: 23/10/2020

Editora associada: Luciana Alcântara Nogueira

Autor Correspondente: Isabel Cristina Echer

Universidade Federal do Rio Grande do Sul - Porto Alegre, RS, Brasil

E-mail: isabelecher@gmail.com

Contribuição dos autores:

Contribuições substanciais para a concepção ou desenho do estudo; ou a aquisição, análise ou interpretação de dados do estudo - ICE, FGB, BCJ, VMM, SSP

Elaboração e revisão crítica do conteúdo intelectual do estudo - ICE, FGB, BCJ, VMM, SSP, LGC, AFL

Aprovação da versão final do estudo a ser publicado - ICE, FGB, BCJ, VMM, SSP, LGC, AFL

Responsável por todos os aspectos do estudo, assegurando as questões de precisão ou integridade de qualquer parte do estudo - ICE

Copyright $\odot 2021$ Este é um artigo em acesso aberto distribuído nos termos da Licença Creative Commons Atribuição, que permite o uso irrestrito, a distribuição e reprodução em qualquer meio desde que o artigo original seja devidamente citado. 